\title{
Proportional positive airway pressure: a new concept to treat obstructive sleep apnoea
}

\author{
J. Juhász*,\#, H. Becker", W. Cassel ${ }^{\#}$, S. Rostig ${ }^{\#}$, J-H. Peter ${ }^{\#}$
}

Proportional positive airway pressure: a new concept to treat obstructive sleep apnoea. J. Juhász, H. Becker, W. Cassel, S. Rostig, J-H. Peter. C) ERS Journals Ltd 2001. ABSTRACT: Proportional positive airway pressure (PPAP) was designed to optimize airway pressure for the therapy of obstructive sleep apnoea (OSA). In a randomized crossover prospective study, the clinical feasibility of PPAP and its immediate effects on the breathing disorder and sleep in comparison with continuous positive airway pressure (CPAP) was evaluated. Twelve patients requiring CPAP therapy underwent CPAP and PPAP titration in a random order.

Obstructive and mixed respiratory events could be completely abolished with both forms of treatment. This efficacy could be achieved at a significantly lower mean mask pressure during PPAP titration $\left(8.45 \pm 2.42 \mathrm{cmH}_{2} \mathrm{O}\right)$ compared to CPAP $\left(9.96 \pm 2.7 \mathrm{cmH}_{2} \mathrm{O}\right)(\mathrm{p}=0.002)$. The mean minimal arterial oxygen saturation $\left(\mathrm{S}_{\mathrm{a}}, \mathrm{O}_{2}\right)$ $(82.8 \pm 6.5 \%)$ on the diagnostic night increased significantly $(\mathbf{p}<0.001)$ to an average $\mathrm{S}_{\mathrm{a}, \mathrm{O}_{2}}$ of $93.35 \pm 1.71 \%$ and $93.19 \pm 2.9 \%$ during CPAP and PPAP titration. Total sleep time, slow wave sleep and rapid eye movement (REM) sleep increased significantly by the same amount during both CPAP and PPAP titration $(p<0.001)$, while sleep stage nonrapid eye movement (NREM) 1 and 2 decreased. Six patients preferred the PPAP titration night, four patients did not have a preference, and two patients preferred CPAP.

The present data show that proportional positive airway pressure is as effective as continuous positive airway pressure in eliminating obstructive events and has the same immediate effect on sleep. The lower average mask pressure during proportional positive airway pressure implies potential advantages compared to continuous positive airway pressure. Proportional positive airway pressure presents a new effective therapeutic approach to obstructive sleep apnoea.

Eur Respir J 2001; 17: 467-473.
*Klinik für Schlafstörungen Bayerisch Gmain, Germany. ${ }^{\#}$ Zentrum für Innere Medizin, Philipps-Universität, Schlafmedizinisches Labor Marburg, Germany.

Correspondence: J. Juhász, Klinik für Schlafstörungen, Reichenhaller Str. 20, 83457 Bayerisch Gmain, Germany Fax: 498651770105

Keywords: Continuous positive airway pressure

proportional positive airway pressure sleep apnoea

sleep stages

Received: October 141999

Accepted after revision September 15 2000

This study was supported by a research grant from Respironics Inc., Murrysville, USA.
Although nasal continuous positive airway pressure (CPAP) represents the state-of-the-art therapy for obstructive sleep apnoea syndrome (OSAS) [1-3], more attention has recently been paid to unfavourable clinical effects and limiting factors, such as the intolerance of pressure $[4,5]$ patient compliance and interface difficulties [6-8]. While bilevel positive airway pressure therapy may be effective at lower expiratory pressure [9], it was not found to be superior to CPAP with regards to long-term compliance [10]. Despite the undeniable efficacy of these mechanical treatments, they do not provide an optimal pressure adjustment during a breathing cycle.

A new concept was conceived to optimize the airway pressure for comfort while compensating for all collapsing forces in proportion to the airflow generated by the patient (proportional positive airway pressure (PPAP)) [11]. In a recent article FARRÉ et al. [12] published a similar approach using a flow-dependent positive airway pressure. They found that adopting the applied nasal pressure to the instantaneous flow was effective in a model as well as to treat sleep disordered breathing in nine patients. However, they did not complete a whole night of study and did not evaluate the effects on sleep.
In a randomized crossover prospective study PPAP therapy in patients with OSAS to CPAP treatment was compared. The aim of the study was to assess whether: 1) PPAP is an effective method to treat obstructive sleep apnoea, and, 2) if the dynamically changing pressure disturbs sleep with special regard to pressure relief during exhalation.

\section{Method}

\section{Patients}

The study was completed January-July 1996 in the sleep laboratory of the Phillips-University in Marburg, Germany. Twelve patients with obstructive sleep apnoea (OSA) requiring CPAP therapy were randomly selected (table 1). Sleep disordered breathing was assessed during the diagnostic polysomnography (baseline measurement) in the sleep laboratory preceding the titration nights. Patients gave written informed consent to participate in the study. The ethics committee of the University of Marburg approved the study protocol. 
Table 1. - Anthropometric data

\begin{tabular}{|c|c|c|c|c|c|}
\hline Subjects & Age yr & $\mathrm{BMI} \mathrm{kg} \cdot \mathrm{m}^{-2}$ & IVC $\%$ & FEV1 \% & FEV1/IVC $\%$ \\
\hline 1 & 51 & 40.4 & 72.1 & 66 & 90.5 \\
\hline 2 & 47 & 26.1 & 96.9 & 102 & 104 \\
\hline 3 & 55 & 30.7 & 97.8 & 105 & 106 \\
\hline 4 & 64 & 35.1 & 80.2 & 75.9 & 93.1 \\
\hline 5 & 51 & 39.4 & 80 & 74.7 & 91.9 \\
\hline 6 & 55 & 28.6 & 64.8 & 74.2 & 116 \\
\hline 7 & 54 & 40.9 & 91.9 & 96.4 & 105 \\
\hline 8 & 32 & 44.3 & 94 & 106 & 112.8 \\
\hline 9 & 48 & 40.2 & 116 & 106 & 95.7 \\
\hline 10 & 30 & 29.1 & 109.8 & 96.9 & 87.2 \\
\hline 11 & 49 & 31.9 & 94.5 & 94.3 & 98.6 \\
\hline 12 & 50 & 27.5 & 85.5 & 89.8 & 109 \\
\hline Mean \pm SD & $48.83 \pm 9.47$ & $34.52 \pm 6.28$ & $90.29 \pm 14.73$ & $90.6 \pm 14.28$ & $100.81 \pm 9.33$ \\
\hline
\end{tabular}

BMI: body mass index; IVC: inspiratory vital capacity as per cent of predicted; FEV1: forced expiratory volume in one second as per cent of predicted; FEV1/IVC presented as $\%$.

The concept and technical background of proportional positive airway pressure

During spontaneous breathing a pressure gradient exists within the airways. This pressure difference drives the airflow into and out of the lungs (dynamic condition). During inspiration, the lungs and upper airways are at subambient pressure. In OSAS this pressure acts upon the airway and contributes to its narrowing and/or collapse [13]. During exhalation a positive pressure gradient exists between the intrapulmonary airways and the outer ambient. This positive pressure gradient helps to keep the airway open during exhalation. At the end of exhalation the pressure gradient is zero (static conditions) and the airway is unaffected by respiratory efforts. Any collapse of the airway at end-expiration is purely a function of the structure of the airway tissues, muscle tone, and body position.

The goal of PPAP is to provide a base pressure ( $P$ basal) to overcome static collapsing forces (dependent on position, skeletal structure, shape and tone of airway tissue) while compensating for variable collapsing forces (dependent on respiratory efforts, flow effects) by raising the pressure during inspiration, as well as lowering the pressure below Pbasal to provide comfort during exhalation, in proportion to flow rate. PPAP is intended to provide positive airway pressure to a patient via a nasal interface to treat OSAS. The pressure delivered to the patient is a function of the patient flow rate. This function can be described as follows:

$$
P_{\text {delivered }}=P \text { basal }+(\text { Flow } \times \text { Gain })
$$

where $P$ delivered is the pressure delivered to the patient interface at a given moment. Flow is the estimated patient flow; and Gain is the constant used to augment pressure based on the flow rate (P/Flow).

$$
\begin{gathered}
P \text { inhalation }=P \text { basal }+(\text { Flow } \times \text { Gaininsp }) \\
P \text { exhalation }=P \text { basal }+(\text { Flow } \times \text { Gainexhale })
\end{gathered}
$$

where Gaininsp is the constant used during inspiration (positive flow) to boost pressure based on the flow rate
(= IPAP/Flowinsp); Gainexhale is the constant used during exhalation (negative flow) to reduce pressure based on the flow rate $(=\mathrm{PR} /$ Flowexp). Inspiratory pressure difference over $P$ basal $(\triangle \mathrm{IPAP})$ and pressure relief below $P$ basal (PR) values were set manually during titration. Gain has values in the range of $0-10 \mathrm{cmH}_{2} \mathrm{O} \cdot \mathrm{L}^{-1} \cdot \mathrm{s}^{-1}$ for inspiration and has values in the range of $0-4 \mathrm{cmH} \mathrm{H}_{2} \mathrm{O} \cdot \mathrm{L}^{-1} \cdot \mathrm{s}^{-1}$ for exhalation.

Figure 1a shows a typical patient flow pattern and the resulting pressure delivered with the inspiratory gain. With different gain settings, any number of waveforms can be generated. Depending on the gain settings, the pressure waveform can follow any optional curve both for inspiration and exhalation (fig. 1b).

In comparison with CPAP or bilevel PAP, the base pressure during PPAP is equivalent to the pressure necessary to overcome any static collapsing forces at end-expiration. This is the expiratory positive airway pressure (EPAP) typically used in bilevel therapy. An inspiratory pressure difference over $P$ basal $(\mathrm{EPAP}+\Delta \mathrm{I}-$ PAP) provides a pressure level necessary to overcome dynamic collapsing forces during inspiration (equivalent to CPAP level and IPAP during bilevel therapy). A temporary pressure relief (PR) can be set to lower the mask pressure below $P$ basal that augments exhalation at the starting phase of expiration (fig. 2). The expiratory flow is associated with a positive expiratory pressure gradient in the airways that results in a dynamic support to the upper airways preventing any dynamic collapsing forces during exhalation.

The prototype used was based on the blower, valve and pneumotachograph configurations from the BiPAP $\mathbb{R}$ (Respironics Inc., Murrysville, USA) system controlled by an external computer. The respiratory parameters were continuously displayed on a monitor and also stored on computer. Technical hurdles consisted of the detection of patient flow in an open system, determining leak as a function of pressure, pressure control and rapid pressure response.

\section{Titration of proportional positive airway pressure}

The titration of the effective pressure setting was accomplished manually. First, an effective CPAP to 

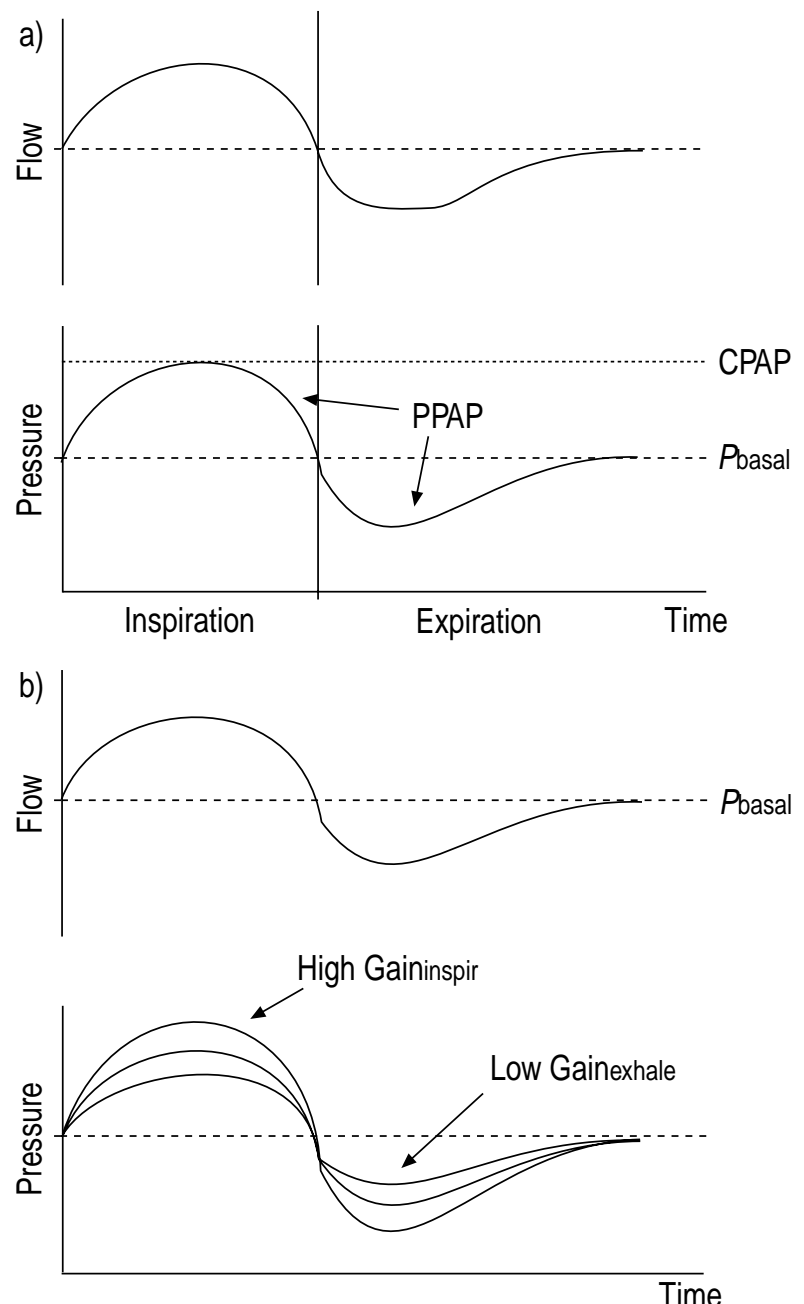

Fig. 1. - Applying a flow signal derived from a normal respiratory pattern will result in a pressure rise above baseline pressure $(P$ basal) during inspiration and a pressure drop below $P$ basal during exhalation. When patient flow is near to zero (beginning and end of inspiration, beginning and end of exhalation) the pressure approaches $P$ basal. The pressure wave form and the flow wave form exhibit a similar run. b) A high setting for the constant used during inspiration (Gaininsp) would lead to the pressure trace following the uppermost curve during inhalation. This could be combined with a low setting for the constant used during exhalation (Gainexhale), leading to a wave form that followed the uppermost curve during exhalation. CPAP: continuous positive airway pressure.

abolish apnoeas and hypopnoeas and then an expiratory PR $\left(2-3 \mathrm{cmH}_{2} \mathrm{O}\right)$ to facilitate exhalation were adjusted for. After ensuring that no further occlusion occurred, the Pbasal was gradually decreased to a minimally effective expiratory level, with a synchronous adjustment of $\triangle I P A P$ to maintain the effective maximal inspiratory pressure (MIP) (fig. 2).

\section{Study design and measurements}

All patients underwent a diagnostic polysomnography followed by the CPAP or PPAP titration, which was performed in a random order. Patients were unaware of the actual mode that was used. Treatment

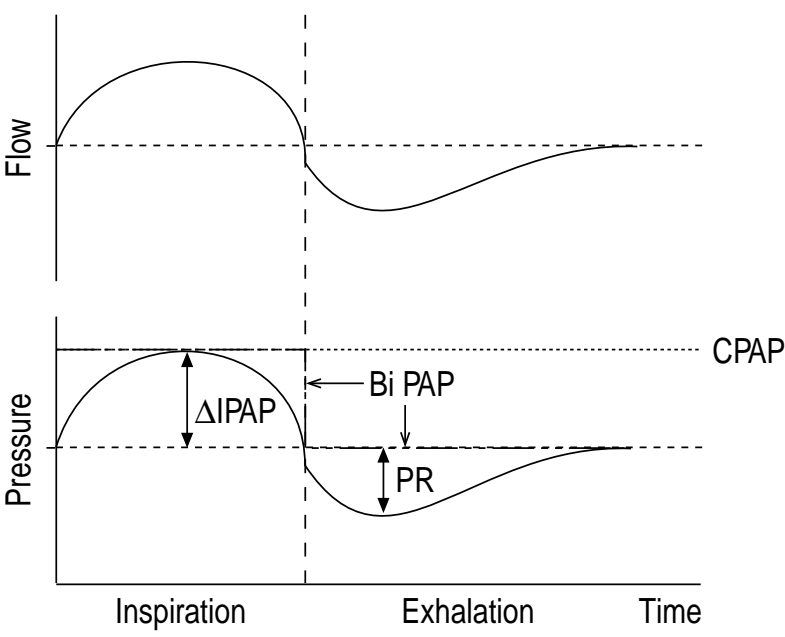

Fig. 2. - Proportional positive airway pressure (PPAP) waveform (-) in relation to continuous positive airway pressure (CPAP; ….) and bilevel pressure (BiPAP; stepwise line (--.) curves during a breathing cycle. The thin broken line represents baseline pressure $(P$ basal $)$ for PPAP.

was accomplished with the PPAP device designed for this clinical study, which could be used either in CPAP or in PPAP mode. PPAP and CPAP titration was carried out manually according to the polysomnographic recording. The criterion for an effective pressure adjustment was abolishing all obstructive events including snoring, apnoeas/hypopnoeas as well as episodes of flow limitation, assessed visually as a flattening of the flow tracings during inspiration. The following parameters were recorded continuously on chart recorders (ED-16 and UD-8, Madaus Schwarzer, Munich, Germany) and on a personal computer (PC) two electroencephalogram (EEG) leads (C3/A2, C4/A1), two electro-oculogram (EOG) leads, two electromyogram (EMG) leads (chin, tibialis), mask pressure, snoring sounds, thoracic and abdominal breathing movements by respiratory inductive plethysmography (Respitrace $\AA$, Ambulatory Monitoring, Inc., Ardsley, USA), and pulse oximetry (Biox 3700, Ohmeda, Boulder, USA). Airflow was monitored using the pneumotachograph of the PPAP-machine. After each night, the patients were asked to fill out a questionnaire to score their subjective feelings regarding the PAP titration.

\section{Data collection and analysis}

Primary outcome measure was the effectiveness in terms of the respiratory disturbance index (RDI). Primary outcome measures for the effects on sleep were total sleep time (TST), wake time (WT), sleep stage distribution and the number of arousals. Secondary measures consisted of mean effective mask pressure, obstructive and central respiratory events, mean arterial oxygen saturation $\left(\mathrm{S}_{\mathrm{a}}, \mathrm{O}_{2}\right)$ and a subclassification of arousals related to obstructive events, nonobstructive events (central events and spontaneous arousal) or periodic limb movements (PLM).

Polysomnography and sleep stage scoring were completed according to the criteria by RECHTSCHAFFEN 
and KALES [14]. RDI, obstructive and nonobstructive events (apnoeas, hypopnoeas) were scored visually and were assessed separately both for the whole titration night and for the time period under effective PAP, and were compared with data from the diagnostic night. The mean values of TST, WT, nonrapid eye movement (NREM) 1, 2, 3-4 sleep stages and rapid eye movement (REM) sleep time from diagnostic and both titration nights were compared by one-way analysis of variance (ANOVA). Sleep time, RDI and arousal indices related to different respiratory events were also calculated during the periods of effective pressure and were analysed by ANOVA.

The differences in various pressure settings (CPAP versus Pbasal and MIP during PPAP) were analysed and mean mask pressures using a two-tailed t-test. Mean mask pressure both for CPAP and PPAP titration was calculated as the integral of the product of the pressure and time over 20 consecutive regular breathing cycles in stage 2 NREM sleep. The breathing cycles were selected randomly in identical body position during PPAP versus CPAP titration.

The mean values of the $\mathrm{Sa}_{\mathrm{a}} \mathrm{O}_{2}$ for diagnostic and treatment nights were compared. The average values of minimal $\mathrm{Sa}_{\mathrm{a}} \mathrm{O}_{2}$ during the diagnostic night were collected. For both CPAP and PPAP titration nights, the mean $\mathrm{Sa}, \mathrm{O}_{2}$ values were calculated by integrating the product of $\mathrm{Sa}_{\mathrm{a}} \mathrm{O}_{2}$ and time during the entire period under effective pressure. The differences were evaluated using a two-tailed t-test.

The strength of the linear relationship between the variables was analysed by the Pearson product moment correlation. Statistical significance was assumed at $\mathrm{p}<0.05$.

\section{Results}

\section{Effects on breathing disorders}

During the diagnostic measurement all patients presented with severe obstructive sleep disordered breathing with a mean RDI of 82.9 \pm 49.27 . All obstructive and mixed apnoeas and hypopnoeas could be completely abolished during both titration nights. The numbers of central events increased during both CPAP $\left(4.17 \pm 8.16 \cdot h^{-1}\right)$ and PPAP $\left(8.17 \pm 17.4 \cdot h^{-1}\right)$ titration compared to baseline $\left(1.67 \pm 3.17 \cdot \mathrm{h}^{-1}\right)$, however, the difference in central events during CPAP versus PPAP titration was not significant. During arousals on awakenings a large tidal volume corresponding to the first breath that did not persist afterwards, was noticed.

The mean minimal $\mathrm{Sa}_{\mathrm{a}} \mathrm{O}_{2}$ during baseline (82.83 \pm $6.46 \%)$ increased significantly $(\mathrm{p}<0.001)$ to an average $\mathrm{Sa}_{2} \mathrm{O}_{2}$ of $93.35 \pm 1.71 \%$ and $93.19 \pm 1.56 \%$ during the time period under effective pressure with CPAP and PPAP respectively.

\section{Effective pressure levels}

The overall pressure settings for each patient are shown in table 2 . The effective mask pressure was $10.33 \pm 2.9 \mathrm{cmH}_{2} \mathrm{O}($ mean \pm SD) for the CPAP titration nights. The mean base pressure (EPAP) was $8.83 \pm 2.66$ $\mathrm{cmH}_{2} \mathrm{O}$, the mean $\triangle$ IPAP was $1.54 \pm 0.84 \mathrm{cmH}_{2} \mathrm{O}$ and the mean pressure relief was $-2.25 \pm 0.34 \mathrm{cmH}_{2} \mathrm{O}$ for the PPAP titration nights. The mean difference in $P$ basal during CPAP versus PPAP titration nights was $1.5 \pm$ $1.31 \mathrm{cmH}_{2} \mathrm{O}(\mathrm{p}<0.002)$. The MIP during PPAP titration (the algebraic sum of $P$ basal and $\triangle$ IPAP) was the same on average $\left(10.38 \pm 2.77 \mathrm{cmH}_{2} \mathrm{O}\right)$ as pressure settings during CPAP titration $\left(10.33 \pm 2.9 \mathrm{cmH}_{2} \mathrm{O}\right)$. However, the mean mask pressure during PPAP titration $\left(8.45 \pm 2.42 \mathrm{cmH}_{2} \mathrm{O}\right)$ was significantly lower compared to CPAP $\left(9.96 \pm 2.7 \mathrm{cmH}_{2} \mathrm{O}\right)$ the mean difference being $1.51 \pm 1.3 \mathrm{cmH}_{2} \mathrm{O}(\mathrm{p}=0.002)$ (fig. 3). The lower mean mask pressure showed a positive correlation with the lower $P$ basal $(r=0.98)$ during PPAP. The differences in mean mask pressure during CPAP versus PPAP titration correlated strongly with differences in CPAP settings versus Pbasal $(\mathrm{r}=0.96)$. The standardized skewness and kurtosis values for the sample were within the expected range for data from a normal distribution.

\section{Effects on sleep}

Total sleep time (TST) increased from baseline

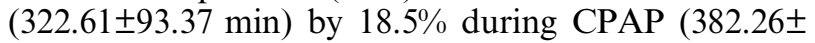
$69.64 \mathrm{~min})$ and $18 \%$ during PPAP (380.63 $\pm 81.41 \mathrm{~min})$, while wake time decreased by $28.2 \%$ and $25.3 \%$ respectively. Sleep stage NREM 1 and 2 shortened during both CPAP and PPAP titration to the same degree, while slow wave sleep and REM sleep increased (fig. 4). The changes in NREM stage 2, slow wave sleep and REM sleep during both titration nights were significant $(p<0.001)$ compared to the diagnostic night, but there was no difference between CPAP and PPAP. Sleep time under effective mask pressure was $243.77 \pm 67.95 \mathrm{~min}$ during CPAP titration and 199.71 \pm 100.52 min during PPAP titration $(\mathrm{p}=0.37)$.

The arousal index significantly decreased during both treatment nights compared to the diagnostic night. There was no significant difference between the arousal index under CPAP $\left(18.2 \pm 6.1 \mathrm{~L} \cdot \mathrm{h}^{-1}\right)$ and under PPAP $\left(17 \pm 5.8 \cdot h^{-1}\right)$.

\section{Patients' judgement}

Six out of the twelve patients preferred the second titration night, two patients chose the first titration night and four patients did not find any difference between the titration nights. Six patients preferred PPAP titration, two patients CPAP titration and four patients did not have a preference.

\section{Discussion}

This report summarizes the first comprehensive clinical results demonstrating that PPAP is as effective as CPAP in eliminating both obstructive and mixed respiratory events. The dynamically changing mask pressure within a breathing cycle during PPAP did not disturb sleep or produce an increased number of arousals. 
Table 2. - Pressure settings for effective mask pressures

\begin{tabular}{|c|c|c|c|c|c|c|c|}
\hline Subjects & CPAP & EPAP & $\triangle I P A P$ & MIP & PR & MMCPAP & MMPPAP \\
\hline 1 & 11 & 11 & 1 & 12 & -2.5 & 10.7 & 10.4 \\
\hline 2 & 9 & 7 & 1 & 8 & -2 & 8.8 & 7 \\
\hline 3 & 6 & 5 & 2 & 7 & -2 & 6.4 & 5 \\
\hline 4 & 14 & 12 & 3 & 15 & -2 & 13.6 & 12.1 \\
\hline 5 & 11 & 8 & 2 & 10 & -2 & 10.8 & 8.3 \\
\hline 6 & 14 & 13 & 1 & 14 & -2 & 12.7 & 11.8 \\
\hline 7 & 15 & 12 & 1 & 13 & -2 & 14.5 & 10.8 \\
\hline 8 & 10 & 10 & 1 & 11 & -2 & 9.7 & 9.5 \\
\hline 9 & 8 & 7 & 1 & 8 & -2.5 & 7.8 & 6.8 \\
\hline 10 & 7 & 6 & 0.5 & 6.5 & -2.5 & 6.8 & 5.4 \\
\hline 11 & 8 & 8 & 3 & 11 & -2.5 & 7.1 & 7.5 \\
\hline 12 & 11 & 7 & 2 & 9 & -3 & 10.6 & 6.8 \\
\hline Mean \pm SD & $10.33 \pm 2.9$ & $8.83 \pm 2.66^{*}$ & $1.54 \pm 0.84$ & $10.38 \pm 2.77$ & $-2.25 \pm 0.34$ & $9.96 \pm 2.7$ & $8.45 \pm 2.42 *$ \\
\hline
\end{tabular}

MMCPAP: mean mask pressure during CPAP titration; MMPPAP: mean mask pressure during PPAP titration; CPAP: continuous positive airway pressure; EPAP: expiratory positive airway pressure; $\triangle$ IPAP: inspiratory pressure difference over base pressure; MIP: maximal inspiratory pressure; PR: pressure relief. *: $p=0.002$ for MMCPAP compared to MMPPAP and CPAP compared to EPAP.

The attention of clinicians has recently been gradually drawn to some clinical problems related to the use of CPAP [4, 8]. The problem of unnecessarily high expiratory pressure during CPAP was addressed by introducing bilevel PAP [9]. The undesirable cardiorespiratory consequences of CPAP in patients with underlying heart and/or respiratory disease has been published [5]. Although both CPAP and bilevel PAP a)

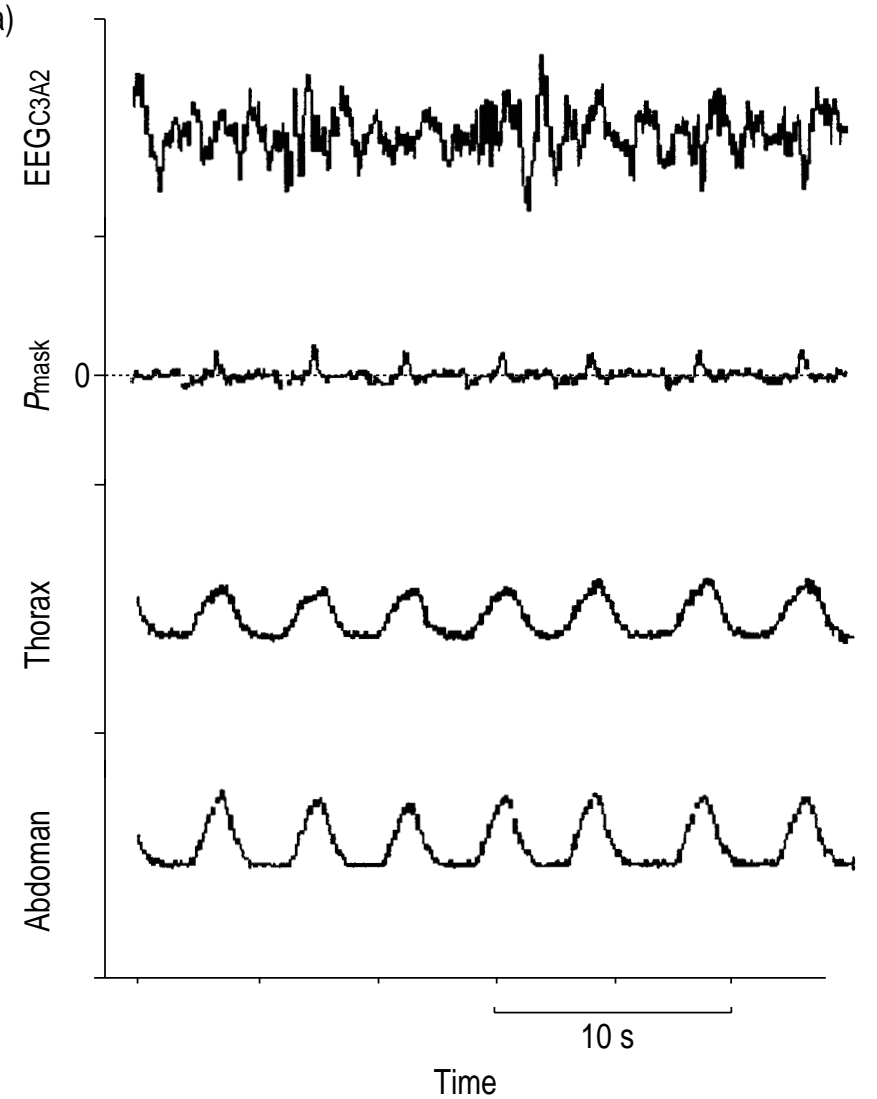

b)

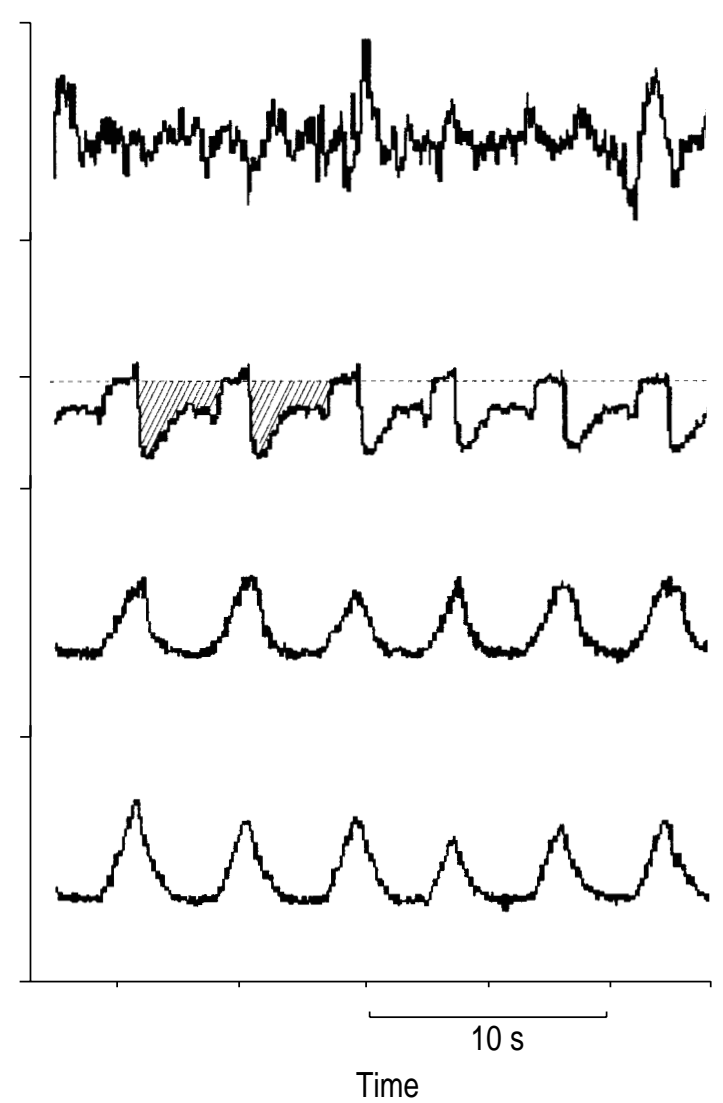

Fig. 3. - Effective mask pressure during a) continuous positive airway pressure (CPAP) versus b) proportional positive airway pressure (PPAP) titration. The dotted line on PPAP titration indicates effective CPAP level. The shaded area above the pressure tracing represents the entire amount of "pressure relief" during PPAP titration. The scale for Pmask is identical for CPAP and PPAP. EEG: electroencephalogram; Pmask: mask pressure; CPAP titration: CPAP: $8 \mathrm{cmH}_{2} \mathrm{O}$; mean mask pressure (MMP): $7.8 \mathrm{cmH}_{2} \mathrm{O}$; PPAP titration: PPAP: $7 \mathrm{cmH}_{2} \mathrm{O}$; inspiratory pressure difference over baseline pressure; pressure relief below baseline pressue: $2.5 \mathrm{cmH}_{2} \mathrm{O}$; $\mathrm{MMP}$ $6.8 \mathrm{cmH}_{2} \mathrm{O}$. 


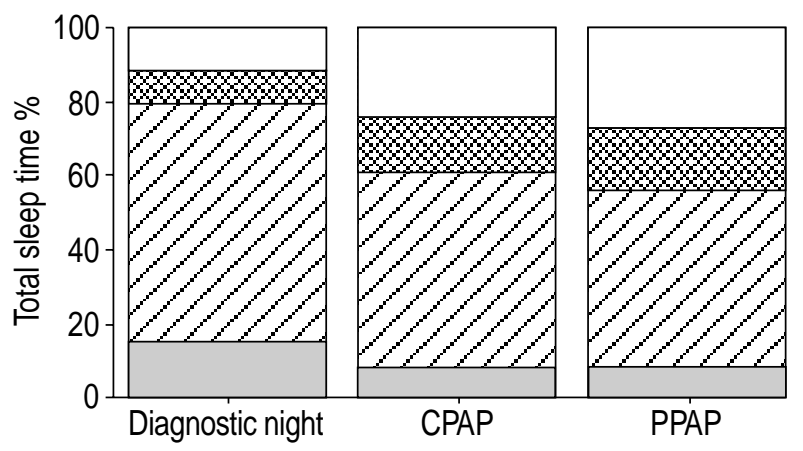

Fig. 4. - Changes in sleep stages (ST) during different titration nights. Values are presented as percentage of total sleep time CPAP: continuous positive airway pressure; PPAP: proportional positive airway pressure. : ST1; $\mathbb{Q}:$ ST2; $\square$ : ST3-4; $\square$ : ST rapid eye movement.

therapy is effective and well tolerated by the majority of the patients, it is still an unsolved problem that current mechanical therapies do not provide the minimal pressure wave form during the breathing cycle, sufficient to overcome airway collapse. The concept of a flowdependent PAP was the first approach in taking the advantage of variable collapsing forces to reduce the pressure both during inspiration and expiration.

\section{Approaches to overcome upper airway obstruction}

CPAP acts to avoid airway narrowing by supplying positive pressure to mechanically splint the airway $[15$, 16]. This splinting pressure is constant and is optimized during sleep in order to be effective in preventing narrowing or collapse of the upper airway. CPAP levels are typically set to raise the pressure level in the entire respiratory system to the level required to overcome any collapsing forces that result from the subambient pressure generated during inspiration. However, this approach exposes the patient to pressure values that are higher than the pressure needed to support the airway for much of the breathing cycle. The inspiratory pressure in bilevel systems is set in a similar manner. Bilevel devices seek to supply diminished expiratory pressure to support the airway at the end of exhalation. CPAP therapy ignores the variations in pressure requirements and provides splinting at a constant pressure level. Therefore, it does not offer optimal pressure adjustment since the CPAP level is based on the peak pressure requirements during inspiration. Bilevel systems take advantage of the different pressure requirements during inspiration and expiration. Nevertheless, bilevel systems do not offer optimal therapy either, since IPAP is based on peak needs during inspiration and the EPAP is based on the support needed at end-expiration.

PPAP seeks to provide only the pressure that is necessary to prevent collapse at any given moment during the breathing cycle. This will result in supplying maximal pressure corresponding to maximal negative inspiratory pressures and providing minimal pressure support corresponding to peak positive expiratory pressures in the airway. This is the major technical progress of the PPAP system that considers the physiological dynamic supportive forces (e.g. expiratory positive pressure gradient) during a breathing cycle. Thus, PPAP provides sinusoidal airway pressure waveforms approaching physiological requirements.

\section{The effectiveness of PPAP}

PPAP eliminated all obstructive apnoeas and hypopnoeas at a significantly lower mean mask pressure compared to CPAP. The maximal inspiratory pressure values during PPAP titration were almost identical to the effective pressure settings during CPAP (table 2). This explained the effectiveness of PPAP therapy at lower mean mask pressures. The lower mean mask pressure was the result of a lower Pbasal during PPAP-titration. The lower $P$ basal and mean mask pressure with the same effectiveness during PPAP therapy lends support to the assumption that the application of PPAP may also be associated with more physiological mechanical conditions in the respiratory system (e.g. pressure/volume relations) by avoiding unnecessarily high pressures in the lung compared to CPAP (fig. 3). This would carry clinical importance in patients who have trouble with excessive PAP since CPAP increases end-expiratory lung volume [17] and can unfavourably affect the cardiorespiratory function $[2,18,19,20]$.

Two patients presented with 18 and 61 central apnoeas/hypopnoeas during PPAP-titration. They had 29 and two central events respectively during CPAPtitration. The latter patient had a body mass index (BMI) of $44.3 \mathrm{~kg} \cdot \mathrm{m}^{-2}$ and daytime blood gases showed slight hypoxaemia (oxygen tension in arterial blood $\left.\left(\mathrm{Pa}, \mathrm{O}_{2}\right): 77 \mathrm{mmHg}\right)$ and hypocapnia $\left(\mathrm{Pa}_{\mathrm{a}} \mathrm{CO}_{2}\right.$ : $38 \mathrm{mmHg}$ ). Unstable ventilatory control and the additive ventilatory effect of PPAP could have been the cause for the higher number of central events in these patients [21]. In the majority of the patients, there were no central events or no differences in central events $\left(<10\right.$ events'night $\left.{ }^{-1}\right)$ during CPAP versus PPAP titration (5 pts). The presence of central events in some (essentially predisposed) patients on PPAP should be carefully assessed in further studies, since it could represent a potential drawback to the method. Patients with OSAS have a typically disrupted sleep structure with an increased number of arousals and increased proportion of NREM sleep stages 1 and 2 and depressed slow wave sleep (SWS) as well as REM sleep. CPAP was shown to eliminate obstructive eventrelated arousals, to increase SWS and REM sleep and to decrease NREM sleep stages 1 and 2, even during the first night $[22,23]$. The present results proved that the titration with PPAP affected the sleep structure in the same manner, as did CPAP. This was presented by the overall improvement in TST, the distribution of different stages and decrease in the number of arousals.

Most of the patients subjectively found the second titration night more comfortable, suggesting habituation to the positive airway pressure treatment. From the responses of the patients, the authors are confident that PPAP was found to be at least as, and not less, comfortable than CPAP. 
A limitation of the present study, was that the critical pressure in the pharynx was not assessed, and an objective measure of flow limitation was not used, which was only visually controlled on the airflow tracing recorded by pneumotachograph. In the protocol the titration of effective settings (CPAP, DIPAP, EPAP, PR) was performed manually on a "trial and error" basis. That could also explain the relatively small but still statistically significant difference in mean effective mask pressures.

In conclusion, proportional positive airway pressure was found to be as effective as continuous positive airway pressure in eliminating obstructive apnoeas and hypopnoeas, and it produced a comparable effect on sleep. The lower mean mask pressure with the same efficacy suggests the potential advantage for patients having trouble with excessive positive airway pressure. These results demonstrate that proportional positive airway pressure is a clinically feasible effective technical approach for the treatment of obstructive sleep apnoea. Further clinical studies on a larger group of patients should assess the long-term efficacy of, and patient compliance with proportional positive airway pressure therapy.

\footnotetext{
Acknowledgements. The authors would like to thank M. Estes (Respironics Inc.) for his technical co-operation during the clinical measurements and for providing the technical description of the equipment.
}

\section{References}

1. Sullivan CE, Issa FG, Berthon-Jones M, Eves L. Reversal of obstructive sleep apnoea by continuous positive airway pressure applied through the nares. Lancet 1981; 1: 862-865.

2. Becker H, Stammnitz A, Schneider H, Peter JH, v. Wichert P. Die nasale "continuous positive airway pressure (nCPAP)" - Therapie bei obstruktiven schlafbezogenen Atmungsstörungen. Dtsch med Wschr 1995; 120: 783-789.

3. Smith PL, Hudgel DW, Olson LG, et al. Indications and standards for use of nasal continuous positive airway pressure (CPAP) in sleep apnea syndromes. ATS statement. Am J Respir Crit Care Med 1994; 150: 1738-1745.

4. Stammnitz A, Becker H, Schneider H, Peter JH, v. Wichert P. Fehler und Gefahren bei der Einleitung der nasalen Beatmungstherapie obstruktiver Schlafapnoen. Pneumologie 1995; 49: 190-194.

5. Juhász J, Schillen J, Urbigkeit A, Ploch T, Penzel T, Peter JH. Unattended CPAP calibration: clinical relevance and cardiorespiratory hazards of the method. Am J Respir Crit Care Med 1996; 154: 359-365.

6. Kribbs NB, Pack AI, Kline LR, et al. Objective measurement of patterns of nasal CPAP use by patients with obstructive sleep apnea. Am Rev Respir Dis 1993; 147: 887-895.
7. Reeves-Hoché MK, Meck R, Zwillich CW. Nasal CPAP: an objective measurement of compliance. $\mathrm{Am}$ J Respir Crit Care Med 1994; 149: 149-154.

8. Hudgel DW. Treatment of obstructive sleep apnea. A review. Chest 1996; 109: 1346-1358.

9. Sanders MH, Kern N. Obstructive sleep apnea treated by independently adjusted inspiratory and expiratory positive airway pressure via nasal mask. Physiologic and clinical implications. Chest 1990; 98: 317-324.

10. Reeves-Hoché MK, Hudgel DW, Meck R, Witteman $\mathrm{R}$, Ross A, Zwillich CW. Continuous versus bilevel positive airway pressure for obstructive sleep apnea. Am J Respir Crit Care Med 1995; 151: 443-449.

11. Juhász J, Cassel W, Gutheil T, Becker H, Peter JH. Proportional positive airway pressure for the therapy of obstructive sleep apnea (OSA) (abstract). Eur Respir $J$ 1997; 10: Suppl. 25, 189s.

12. Farré R, Peslin R, Montserrat JM, Rotger M, Navajas D. Flow-dependent positive airway pressure to maintain airway patency in sleep apnea-hypopnea syndrome. Am J Respir Crit Care Med 1998; 157: $1855-1863$

13. Remmers JE, deGroot WJ, Sauerland EK, Anch AM. Pathogenesis of upper airway occlusion during sleep. J Appl Physiol 1978; 44: 931-938.

14. Rechtschaffen A, Kales A. A manual of standardized terminology, techniques and scoring system for sleep stages of human sleep subjects. Washington, D.C., US Government Printing Office, 1968.

15. Rapoport DM, Garay SM, Goldring RM. Nasal CPAP in obstructive sleep apnea: mechanisms of action. Bull Eur Physiopathol Respir 1983; 19: 616-620.

16. Abbey NC, Cooper KR, Kwentus JA. Benefit of nasal CPAP in obstructive sleep apnea is due to positive pharyngeal pressure. Sleep 1989; 12: 420-422.

17. Werchowski JL, Sanders MH, Constantino JP, Sciurba FC, Rogers RM. Inductance plethysmograph measurement of CPAP-induced changes in end-expiratory lung volume. J Appl Physiol 1990; 68: 1732-1738

18. Podszus T, Becker H, Peter JH, v. Wichert P. Left ventricular function under nCPAP ventilation (abstract). Eur Respir J 1989; 2: Suppl. 8, 785s.

19. Slutsky AS. Mechanical ventilation ACCP consensus conference. Chest 1993; 104: 1833-1859.

20. Seymour HI, Genovese J, Tarasiuk A, Scharf SM. Effects of CPAP on pericardial pressure and respiratory system mechanics in pigs. Am J Respir Crit Care Med 1995; 152: 142-147.

21. Skatrud BJ, Dempsey JA. Interaction of sleep state and chemical stimuli in sustaining rhythmic ventilation. J Appl Physiol 1983; 55: 813-822.

22. Issa FG, Sullivan CE. The immediate effects of nasal continuous positive airway pressure treatment on sleep pattern in patients with obstructive sleep apnea syndrome. Electroenceph Clin Neurophysiol 1986; 63: $10-17$.

23. Aldrich M, Eiser A, Lee M, Shipley JE. Effects of continuous positive airway pressure on phasic events of REM sleep in patients with obstructive sleep apnea. Sleep 1989; 12: 413-419. 